\title{
Mental Health Stigma: What is being done to raise awareness and reduce stigma in South Africa?
}

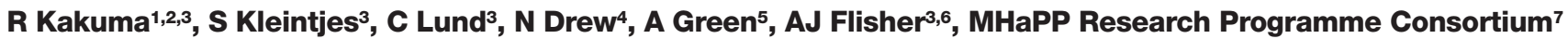 \\ ${ }^{1}$ Health Systems Research and Consulting Unit, Centre for Addiction and Mental Health, Toronto, Canada \\ 2Department of Psychiatry, University of Toronto, Canada \\ 32Department of Psychiatry and Mental Health, University of Cape Town, South Africa \\ 4Department of Mental Health and Substance Abuse, World Health Organization, Geneva, Switzerland \\ 5Nuffield Centre for International Health and Development (NCHD), University of Leeds, United Kingdom \\ ${ }^{6}$ Research Centre for Health Promotion, University of Bergen, Norway
}

${ }^{7}$ The Mental Health and Poverty Project (MHaPP) is a Research Programme Consortium (RPC) funded by the UK Department for International Development (DfID)(RPC HD6 2005- 2010) for the benefit of developing countries. The views expressed are not necessarily those of DfID. RPC members include Alan J. Flisher (Director) and Crick Lund (Co-ordinator) (University of Cape Town, Republic of South Africa (RSA)); Therese Agossou, Natalie Drew, Edwige Faydi and Michelle Funk (World Health Organization); Arvin Bhana (Human Sciences Research Council, RSA); Victor Doku (Kintampo Health Research Centre, Ghana); Andrew Green and Mayeh Omar (University of Leeds, UK); Fred Kigozi (Butabika Hospital, Uganda); Martin Knapp (University of London, UK); John Mayeya (Ministry of Health, Zambia); Eva N Mulutsi (Department of Health, RSA); Sheila Zaramba Ndyanabangi (Ministry of Health, Uganda); Angela Ofori-Atta (University of Ghana); Akwasi Osei (Ghana Health Service); and Inge Petersen (University of KwaZulu-Natal, RSA).

\begin{abstract}
Objective: Stigma plays a major role in the persistent suffering, disability and economic loss associated with mental illnesses. There is an urgent need to find effective strategies to increase awareness about mental illnesses and reduce stigma and discrimination. This study surveys the existing anti-stigma programmes in South Africa. Method: The World Health Organization's Assessment Instrument for Mental Health Systems Version 2.2 and semi-structured interviews were used to collect data on mental health education programmes in South Africa. Results: Numerous anti-stigma campaigns are in place in both government and non-government organizations across the country. All nine provinces have had public campaigns between 2000 and 2005 , targeting various groups such as the general public, youth, different ethnic groups, health care professionals, teachers and politicians. Some schools are setting up education and prevention programmes and various forms of media and art are being utilized to educate and discourage stigma and discrimination. Mental health care users are increasingly getting involved through media and talks in a wide range of settings. Yet very few of such activities are systematically evaluated for the effectiveness and very few are being published in peer-review journals or in reports where experiences and lessons can be shared and potentially applied elsewhere. Conclusion: A pool of evidence for anti-stigma and awareness-raising strategies currently exists that could potentially make a scientific contribution and inform policy in South Africa as well as in other countries.
\end{abstract}

Key words: Mental Health; Stigma; South Africa; Mental Health Promotion

Received: 07-11-2008

Accepted: 04-03-2009

\section{Introduction}

Mental health is increasingly recognized as an important public health and development issue in South Africa.

Neuropsychiatric conditions are the third leading cause of

\section{Correspondence:}

Dr Ritsuko (Ritz) Kakuma, Heath Systems Research and Consulting Unit

Centre for Addiction and Mental Health

33 Russell Street, T311

Toronto, Canada M5S 2 S1

email: ritz.kakuma@gmail.com ; ritsuko_kakuma@camh.net disease burden in South Africa, following HIV/AIDS and other infectious diseases. ${ }^{1}$ Approximately 16.5\% of South Africans interviewed between 2002 and 2004 were suffering from mental disorders in the preceding year. ${ }^{2}$ Similar prevalence estimates have been found among children and adolescents. ${ }^{3}$

Stigma plays a major role in the persistent suffering, disability and economic loss associated with mental illnesses. Persons with mental illnesses are often victimized for their illnesses and face unfair discrimination, such as difficulties accessing housing, 
employment, and other societal roles. They are often mistreated by their family and friends, as well as in the community. ${ }^{4-10}$ Loss of family and/or peer support, loss of employment and lack of access to mental health services (either because of limited access to services or because of the stigma towards seeking mental health care) can worsen their mental illness. It can also place these individuals at increased risk of substance abuse and criminal activities. ${ }^{11-}$ ${ }^{20}$ Many of these individuals consequently end up in the criminal justice system instead of being treated in mental health services. Other factors such as poverty also compound the detrimental effects of stigma on individuals with mental illnesses. ${ }^{21}$

Few studies have investigated levels of stigma in the community towards people with mental illnesses in South Africa. ${ }^{22-24}$ The three studies that have addressed this issue consistently found high levels of stigmatizing attitudes towards individuals with mental health conditions in the communities. Three other studies ${ }^{25-27}$ examined the perceptions of mental health nurses practicing in public hospitals, and found that a significant number of nurses held negative and stereotyped perceptions of mental health care users. One study in South Africa explored the scope and impact of structural stigma and discrimination and found that structural stigma is highly prevalent and stigma-reduction strategies are urgently needed to address these issues to provide high quality mental health care and protect the rights of individuals with mental health conditions. ${ }^{21}$ Structural discrimination refers to policies of the dominant group institutions, and the behaviour of individuals controlling these institutions and implementing policies, unintentionally having a differential and/or harmful impact on minority groups. ${ }^{28}$ Structural stigma refers to the violation of human rights through loss of access to employment, housing, and in some instances, voting, jury duty, holding public office, marriage and parenting. ${ }^{29-33}$

In order to plan strategies for effective anti-stigma campaigns, it is first necessary to ascertain what has been done. This study therefore examines the current antistigma and awareness-raising programmes in South Africa. This research was conducted in the context of a wider international study of mental health policy development and implementation in four African countries: Ghana, South Africa, Uganda and Zambia. ${ }^{34}$ This study, titled the Mental Health and Poverty Project (MHaPP), sets out to investigate the policy level interventions that are required to break the vicious cycle of poverty and mental ill-health, in order to generate lessons for a range of low- and middle-income countries.

\section{Methods}

The study made use of quantitative and qualitative methodologies. Quantitative methods were employed to assess current mental health resources, while qualitative methods were employed to provide an understanding of the processes, underlying issues and interactions between key stakeholders in mental health policy development and implementation. Findings were triangulated where possible, using two or more sources of data or research methods. The fieldwork for the study was conducted between 1 August 2006 and 31 March 2007.

\section{World Health Organization's Assessment Instrument for Mental Health Systems}

Quantitative data regarding the mental health system in South Africa was gathered using the World Health Organization's Assessment Instrument for Mental Health Systems (WHOAIMS) Version 2.2. ${ }^{35}$ The WHO-AIMS tool was developed to assess key components of a mental health system and thereby provide essential information to strengthen these systems. The instrument was developed following the publication of the World Health Report $2001^{36}$, which focused on mental health and provided a set of recommendations that address essential aspects of mental health system development in resource-poor settings. WHO-AIMS 2.2 consists of six domains (covering the 10 World Health Report 2001 recommendations comprising 28 facets and 156 items), of which Domain 5: Public education and links with other sectors is of interest for this study. The three sub-domains are 1) public education and awareness campaigns on mental health; 2) links with other sectors: formal collaboration; and 3) links with other sectors: activities. The instrument includes the WHO-AIMS Excel Data Entry Programme and a template for a narrative report.

The WHO-AIMS spreadsheets were distributed to 1) the nine provincial Departments of Health (DoH); 2) the 17 Mental Health Societies of the South African Federation for Mental Health (SAFMH); 3) professional boards of the Health Professions Council of South Africa for Psychology, Medicine and Occupational Therapy; 4) the South African Nursing Council; and 5) the South African Council of Social Service Professions. Data were requested from services for the 2005 calendar year.

Mental health societies of the SAFMH are community service organizations operating in the field of psychiatric disability, intellectual disability, and/or the promotion of mental well-being. They are registered as separate non-profit organizations with their own management boards and staff. They are not financially accountable to the SAFMH, but are accountable in so far as the standard of service delivery is concerned. ${ }^{37}$ Although other non-government organizations (NGOs) provide services at a local or provincial level, the SAFMH is the only NGO that provides a coordinated national mental health service, is the largest national mental health service provider in the NGO sector and receives government subsidies for its services. It was therefore decided that data would be collected on mental health service provision in the NGO sector from only the SAFMH and its 17 affiliated societies.

The South African health care system is decentralized and therefore mental health services fall under the responsibility of each of the provinces. Thus the provincial mental health coordinators of each of the provincial DoH took responsibility for completing the spreadsheet. They gathered data from regional and district health services as appropriate, with the assistance of health service managers and lead clinicians. In the Mental Health Societies, the head of the relevant society took responsibility for gathering data relevant to service provision at his/her branch and completed the spreadsheet.

\section{Analysis}

The data were entered into nine separate spreadsheets for each of the provincial DoH and a further 17 spreadsheets for 
each of the mental health societies. Data from these spreadsheets were then entered into a national spreadsheet, where numeric data were aggregated. Descriptive analyses of relevant items were conducted.

\section{Semi-structured interviews}

Qualitative methods took the form of semi-structured interviews (SSIs). As stated earlier, the primary purpose of using these instruments was to develop an understanding of the processes of mental health policy development and implementation in South Africa, and the articulation between various systems and interactions among stakeholders.

The sampling of respondents for the SSIs was purposive. Respondents were selected either because they represented key organizations in mental health in South Africa, or they possessed information or had experience that was particularly relevant to study. Respondents were also selected based on the principle of maximum variation, in order to provide as wide a range of perspectives as possible on mental health policy development and implementation in South Africa. Sixty-four SSIs were conducted with various stakeholders using interview schedules that were developed and tailored to the particular stakeholder(s) to be interviewed. The range of stakeholders included policy makers, public sector, nongovernmental and faith-based programme managers, mental health care users and professional organizations.

Interviews were recorded with the permission of respondents and transcribed verbatim. The transcripts were then analyzed using NVivo 7 qualitative data analysis software. A framework analysis approach was adopted ${ }^{38}$, in which certain themes were agreed upon by investigators from all four study countries. These themes were based on the objectives of the study (as set out in the introduction) and for this study, we focused on identifying existing mental health education activities across the country.

\section{Research ethics}

Research ethics permission to conduct this study was obtained from the Research Ethics Committee of the Faculty of Health Sciences, University of Cape Town; the Research Ethics Committee of the Faculty of Humanities, Development and Social Sciences, University of KwaZulu-Natal; and the Research Ethics Committee of the national DoH. Permission to gather data from provincial health services was obtained from the Heads of the 9 provincial Health Departments. Permission to gather data from the 17 Mental Health Societies was obtained from the SAFMH.

Respondents in the SSIs gave informed consent to participate in the study. The identities of interviewees have been kept confidential and all identifying data have been removed from data used in the study.

\section{Results}

\section{Key anti-stigma initiatives}

Survey of the public education and awareness activities across the country has revealed that there are numerous antistigma activities already in place and that several key organizations in both government and non-government sectors, are pushing this agenda forward.

In South Africa, the DoH coordinates and oversees the public awareness and education campaigns. The DoH is assisted by various NGOs including the SAFMH, the South African Depression and Anxiety Group (SADAG), Mental Health Information Centre (MHIC), and other professional, consumer and advocacy bodies. Information about these organizations is provided in Table I.

\section{Table I: Description of mental health organizations}

\begin{tabular}{|c|c|}
\hline Organization & Description \\
\hline $\begin{array}{l}\text { South African Federation for } \\
\text { Mental Health (SAFMH) }\end{array}$ & $\begin{array}{l}\text { A national, not-for-profit, NGO that is affiliated with the African Regional Council for Mental Health and the World } \\
\text { Federation for Mental Health. The SAFMH coordinates, monitors, and promotes services for persons with } \\
\text { psychiatric and/or intellectual disabilities and promotes mental health and wellbeing. They are comprised of } 17 \\
\text { mental health societies and numerous member organizations across the country. Creating public awareness of } \\
\text { mental health issues is one of their main missions and they do so through various activities. }\end{array}$ \\
\hline $\begin{array}{l}\text { South African Depression and } \\
\text { Anxiety Group (SADAG) }\end{array}$ & $\begin{array}{l}\text { A user-led organization based in Johannesburg is another highly active organization in raising awareness and } \\
\text { working towards reducing stigma. In operation since 1995, SADAG is one of the largest mental health support } \\
\text { and advocacy groups in Africa and provides counselling services, mental health awareness programmes, media } \\
\text { campaigns, school talks and rural outreach activities across the country. SADAG boasts about } 180 \text { support } \\
\text { groups across the country and has an extensive referral guide that extends into the most remote regions of } \\
\text { South Africa. }\end{array}$ \\
\hline Mental Health Information Centre (MHIC) & $\begin{array}{l}\text { Based at the University of Stellenbosch in the Western Cape, MHIC serves numerous functions. They provide } \\
\text { telephone information to the public, provide the media with accurate information about mental disorders, support } \\
\text { health professionals and develop and distribute a mental health resource guide annually. The Mental Health } \\
\text { Resource Guide is a comprehensive list of mental health professionals, consumer organizations delivering a } \\
\text { mental health service, and institutions that offer mental health treatment across the country. The guide is updated } \\
\text { annually. The MHIC also produces other publications and participates in consumer-related mental health research. } \\
\text { The MHIC promotes public awareness of mental health issues and research into mental illness, addresses the } \\
\text { stigma associated with mental illness, and promotes good mental health of all South Africans. The MIHC serves } \\
\text { the entire country and hence receives calls from all over South Africa. They are able to provide information in } \\
\text { English, Afrikaans, Xhosa and Zulu. }\end{array}$ \\
\hline
\end{tabular}


All nine provinces have had government agencies and NGOs promote public awareness and education campaigns in the last five years. Only the Western Cape, Free State and Gauteng provinces reported involvement of professional associations in these activities; and only the Western Cape reported involvement of private trusts, foundations and international agencies.

Some of the target audiences of such campaigns include the general population, children and adolescents, women, trauma survivors, ethnic groups and other vulnerable or minority groups. Existing public awareness and education campaigns have targeted professional groups across the country (provinces in brackets) such as health care providers (Gauteng, Western Cape, Free State, North West); complimentary / alternative / traditional healers (Gauteng, Western Cape, Free State); teachers (Gauteng, Western Cape, Free State, Mpumalanga); social service staff (Gauteng, Western Cape); leaders and politicians (Gauteng, Western Cape, Mpumalanga); and other professional groups linked to the health sector (Gauteng, Western Cape, Free State, Mpumalanga).

Formal collaborations in public awareness and education have been formed to different degrees across the provinces and are presented in Table II. Most of the provincial DoHs have formal collaborations with other areas such as primary health and community care, HIV, substance abuse, welfare, and child and adolescent health.

\section{Consumer/User Involvement}

In various parts of the country, mental health care users are becoming involved in NGOs and community activities to provide education about mental illnesses, and obtaining training in skills for supported employment and increasing visibility. Some users are involved in radio shows, distributing posters and pamphlets in various languages, including Zulu and Sotho, (Respondent 39, Mental Health Care User), while others are giving talks in the community.

SADAG has formed partnerships with the communities, leaders, schools, universities, churches, youth groups, prisons, corporations and government, particularly the Directorate of Mental Health and Substance Abuse in the national Department of Health, and are often requested to give talks on mental health issues. They also produce educational materials including free multilingual brochures, audio cassettes and speaking books (books that one can read and hear). The speaking books, available in several languages, are able to provide information to the illiterate population of the country.

We have already started having talks in churches, in halls I'm the one whose doing those talks there [...] and even in the newspapers we do have some articles provided there (Respondent 10, Mental Health Care User)

The Central Gauteng Mental Health Society (CGMHS), one of the 17 Mental Health Societies affiliated with the SAFMH, works to reduce prejudice and misunderstanding through education of the general community and health professionals and monitors reporting of issues on mental and intellectual disabilities in the media for its level of responsibility. The CGMHS launched a Consumer Advocacy Movement in 2005, which aims to empower individuals with mental illness to advocate for themselves and to ensure that their rights are respected, protected and enforced. Members of the CGMHS, both health providers and consumer representatives, present at schools, in both government and private sectors, and health institutions to increase awareness. They also host activities in October during the Mental Health Awareness month where consumers can present their artwork at an arts festival and community members can join in by painting a mural.

The Cape Mental Health Society, another Mental Health Society based in the Western Cape, also encourages consumer involvement through the Cape Consumer Advocacy Body (CCAB). CCAB provides consumers with a platform to voice their views and be proactive in their care. They have representation in various organizations such as the provincial mental health board (Cape Mental Health Board), SAFMH, provincial networks (Western Cape Network on Disabilities), national organizations (Disabled People South Africa), and the psychiatric hospital Board (Valkenberg Hospital Facilities Board) and Catchment Area meetings.

The SAFMH also provides self-advocacy training to empower consumers with skills and knowledge to advocate for themselves, participate in decision-making and facilitate social integration. Consumers are encouraged to contribute to the governance of the SAFMH and to participate in government policy processes through a consumer network.

\section{Table II. Formal collaborations between mental health and other government sectors across provinces.}

\begin{tabular}{|c|c|c|c|c|c|c|c|c|c|c|c|c|c|}
\hline Province & $\mathrm{PHC}$ & $H N$ & Rep & Elder & Subst & Child Pro & Educ & Emp & Hous & Welf & Crim & Child & Other \\
\hline Eastern Cape & $\checkmark$ & $\checkmark$ & $\checkmark$ & $\checkmark$ & $\checkmark$ & $\checkmark$ & $\checkmark$ & $\checkmark$ & $\checkmark$ & $\checkmark$ & $\checkmark$ & $\checkmark$ & $\checkmark$ \\
\hline Free State & $\checkmark$ & $\checkmark$ & $\checkmark$ & $\checkmark$ & $\checkmark$ & $\checkmark$ & $\checkmark$ & $\checkmark$ & $N$ & $\checkmark$ & $\checkmark$ & $\checkmark$ & $\checkmark$ \\
\hline Gauteng & $\checkmark$ & $\checkmark$ & $\checkmark$ & $\checkmark$ & $\checkmark$ & $\checkmark$ & $\checkmark$ & $\checkmark$ & $\checkmark$ & $\checkmark$ & $\checkmark$ & $\checkmark$ & $\checkmark$ \\
\hline Kwazulu-Natal & $\checkmark$ & $\checkmark$ & $\checkmark$ & $\checkmark$ & $\checkmark$ & $N$ & $\checkmark$ & $\checkmark$ & $\checkmark$ & $\checkmark$ & $\checkmark$ & $\checkmark$ & $\checkmark$ \\
\hline Limpopo & -- & -- & -- & -- & -- & -- & -- & -- & -- & -- & -- & -- & -- \\
\hline Mpumalanga & $\checkmark$ & $\checkmark$ & $\checkmark$ & $\checkmark$ & $\checkmark$ & $\checkmark$ & $\checkmark$ & $\checkmark$ & $\checkmark$ & $\checkmark$ & $\checkmark$ & $\checkmark$ & \\
\hline Northern Cape & -- & -- & -- & -- & -- & -- & -- & -- & -- & -- & -- & -- & -- \\
\hline North West & $\checkmark$ & $\checkmark$ & $\checkmark$ & $\checkmark$ & $\checkmark$ & $\checkmark$ & $\checkmark$ & $N$ & N & $\checkmark$ & $\checkmark$ & $\checkmark$ & N \\
\hline Western Cape & $\checkmark$ & $\checkmark$ & $N$ & $\checkmark$ & $\checkmark$ & $\checkmark$ & $\checkmark$ & $N$ & $N$ & $\checkmark$ & $\checkmark$ & $\checkmark$ & \\
\hline
\end{tabular}

Column titles: Primary health care/ community health; HIV/AIDS; Reproductive health; The elderly; Substance abuse; Child protection; Education; Employment; Housing; Welfare; Criminal justice; Child and adolescent health.

$\boldsymbol{J}=$ Yes, $\mathrm{N}=$ No, NA = Not Applicable, -- = Unknown. 


\section{Early Education}

Free State, Gauteng and North West provinces indicated that less than $20 \%$ of primary and secondary schools have schoolbased activities to promote mental health and prevent mental disorders. In the Western Cape 51-80\% of schools have such activities. No other provinces indicated any school-based promotion or prevention activities. Available data precluded exploration into the extent or quality of such interventions. However, interviews with key stakeholders suggested that there is still much work to be done in this area. There were consistent messages from interviewees that mental health education must begin in the schools.

"include mental illness awareness in the school syllabus and to start your foundation with the children" (Respondent 35, Mental Health Care User)

"I think if school children could understand (mental illnesses), I think it would make a huge difference for when they reach adulthood. " (Respondent 48, Mental Health Care User)

An interview respondent demonstrated the importance of beginning with the youth by presenting one particular school in Sekukune Land with a successful programme:

\begin{abstract}
"like I visited schools in Sekukune Land recently and we found that there was one school that really turned their whole performance around by building this kind of supportive environment. By even involving the tribal heads, the whole community, by talking to parents on a regular basis, encouraging people, motivating, getting all the services that work/operate within a certain area to enhance the schools role as the centre of community. And I think that whole vision that we had of education right as from '94 of how to change schools in centres of community, needs to get more attention, we need to be able to succeed on that you know. " (Respondent 2, Policy Maker, Department of Education)
\end{abstract}

Recognizing the need to reach the youth, the Cape Mental Health Society provides a Mental Health Awareness Schools' Programme. This is a preventative, educational and interactive programme that focuses on mental health, positive self-image, depression, life stress management and substance abuse.

\section{Correctional Services}

In the prisons, less than $20 \%$ of police officers have participated in educational activities on mental health in the last five years in Gauteng and Free State. Twenty one to fifty percent have participated in such activities in Mpumalanga. No other provinces reported training activities for police officers.

An interview with a policy maker in the Correctional Services suggested that in the prisons, education is necessary for offenders and for warders.

\begin{abstract}
"... aggressive health education to all of the correctional... offender population. [... I I haven't observed any discrimination by them, [...] but I think we still need to educate our warders because you might find that it's only this warder and others are not aware of that, or they are aware and they're neglecting it, so that we can contribute to the healthcare rendered to these offenders. (Respondent 56, Policy Maker, Correctional Services)
\end{abstract}

Very little information was reported on the awareness raising activities in correction services but the available information suggest that there is relatively little awareness raising activities being implemented in correctional services facilities. Only the SAFMH provides a programme designed to empower police with skills on how to manage a person with a mental illness when requested to assist.

\section{Public awareness raising and the media}

Newspapers, television shows, performing arts, radio shows, brochures and pamphlets are used for international events such as World Mental Health Day, Mental Health Awareness month. Organizations such as the SAFMH, SADAG and MHIC have worked closely with the media in providing accurate information about mental illnesses and promoting mental health.

The SAFMH allocates much of their efforts towards mental health awareness and stigma reduction. They use media as well as various communication materials for distribution in the communities. The SAFMH currently have three mental health campaigns every year. March is Intellectual Disability Awareness month, July is Psychiatric Disability Awareness month, and October is Mental Health/well-being Promotion and Awareness Month. Activities in October are mainly targeted around World Mental Health Day (October 10th), where the focus is more towards prevention through healthy lifestyles rather than diagnosis and treatment. During these months, many members of the SAFMH can be seen, heard and read in the media discussing mental health issues.

The Cape Mental Health Society has also been active in public education through production and distribution of printed media (posters, pamphlets, magazines and newspaper articles), community-based radio, workshops and exhibitions.

SADAG also has weekly media releases to local and national media as well as public service announcements to ensure that mental health issues are raised regularly in various settings. The MHIC works with prominent newspaper and magazine journalists in preparing articles on mental health problems such as depression, panic disorder, social phobia, and obsessive-compulsive disorder. Information on mental health issues is provided to many professional and consumer bodies, including the DoH, the South African Society of Psychiatrists, and SADAG.

The MHIC also gives lectures at many schools and corporations on mental health issues so that they are able to identify common mental illnesses and take appropriate action (for example, refer them to a mental health care professional). The MHIC also presents educational talks and programs to the public and is regularly invited to discuss mental health 
issues on the radio and television. They have also periodically organized theatre productions in Cape Town to raise awareness.

In addition to these activities, the Mental Health Information Centre (MHIC) facilitates the annual National Anxiety Disorders Awareness Week and hosts the national mental health awareness campaign every October (around World Mental Health Day) in collaboration with consumer groups and the pharmaceutical industry. As part of these activities, the MHIC presents an annual media award to honour journalists who report on mental health issues accurately, responsibly and sensibly in newspapers, magazines and on radio/TV/internet.

Through the CGMHS, two theatre productions have been developed, both created by a consumer, entitled Madness Revealed: Chasun's Story and Madness Revealed: Thandi's Story. Chasun's story is based on a true story about a young woman's experience with schizophrenia and addresses issues such as self-identification, self-acceptance, fears around seeking professional care and impact on employment. Thandi's story highlights mental illness in African cultures and depicts the myths around mental illness among many African communities where mental illnesses are often attributed to demonic possession or witchcraft rather than a medical condition. It focuses on an individual with bipolar mood disorder and substance abuse, and forefronts the social exclusion and challenges with maintaining/obtaining employment that often results. Information about possible avenues for care is also provided in the production. Both productions have been presented in numerous communities and schools and are powerful stories that have received high praise and positive feedback. The producers are currently exploring possible sources of funding to take the plays on the road and present them across the country.

\section{Other Activities}

The Human Training Trust projects of the SAFMH capacitate service providers in the community and residential care facilities to promote development and uphold human rights when providing care or working with them. The SAFMH also works towards empowering communities by educating caregivers in the community on the Mental Health Care Act 2002 through workshops on Review Boards and the role of the police.

Furthermore, the SAFMH has a human rights programme which monitors the mental health services as well as social integration procedures and ensures that the human rights are upheld. The Human Rights Violations Register was developed by SAFHM in 2006 in order to record all reported cases of human rights violations of persons with psychiatric or intellectual disability, including stigmatization, discrimination, abuse and neglect.

The Social Integration programme of the SAFMH aims to support social integration in the face of myths, stigmatization, poverty and lack of support systems. The National Office runs sensitization workshops for employers to allow for a supportive environment for individuals with psychiatric or intellectual disabilities.

\section{Evaluation of anti-stigma and awareness raising activities} Although there are significant and seemingly effective mental health education activities occurring across South Africa, lack of reporting in scientific journals and in annual reports of the various organizations about evaluation of these activities indicate that they are not being systematically assessed for their effect on increasing awareness and reducing stigma. Discussions with organizers of such activities demonstrated a general lack of rigorous evaluation of their programmes. None of the respondents indicated that their programmes were systematically evaluated and reported. Rather, their reporting of the impact of such programmes was quite limited and anecdotal. A stronger evaluation culture needs to be instilled across all of the organizations.
" ... if you want to build research culture in a country, which is partly what we want to do... part of what we need to inculcate is a sort of culture of scepticism and inquiry and many people start researching whatever they want to research." (Respondent 1 1, Academic Researcher - Health)

Recommendations by respondents for mental health education and anti-stigma campaigns

Numerous recommendations were made by respondents about strategies that were considered essential. These include:

- Education and awareness-raising through various mediums such as public campaigns, identification of champions or role models, workshops at various settings, media, and information packages

- Personal contact with, or exposure to, people with mental illnesses.

- Education and awareness campaigns at a young age, in the school.

- Collaboration between the DoH and other Departments, i.e., Social Development, Education, Police, and Correctional Services, to include mental health into their agendas.

- Further promotion of the Mental Health Act 2002 as a destigmatization tool.

- Use of other legislations e.g., Employment Equity Act to prevent discrimination.

- The development of guidelines to address reasonable accommodation at the workplace.

- Increased training and exposure of health care professionals in managing individuals with mental illnesses.

- The participation of mental health care users in all stigma reduction strategies.

- Use and monitoring of media to ensure balanced and accurate depiction of mental illnesses.

- Need for community participation in awareness raising activities and increase in knowledge to lessen fear and increase acceptance.

- Need for legislative and financial support for state housing and subsidized housing schemes.

\section{Discussion}

This study has demonstrated that in spite of limited resources for mental health, a number of innovative strategies have been developed to address stigma and improve awareness about mental health in South Africa. These include a variety of 
seemingly culturally appropriate and innovative strategies that make good use of limited resources. Both government and NGOs provide a pool of evidence that could be useful in informing policy in South Africa and other low-resource countries.

The impact of these activities, however, is unknown because there is no formal evaluation and reporting on these programmes. This is particularly important for mental health where cultural issues play a key role in the method and content of the educational material. Although we can borrow from the knowledge gained in other settings, context specific evidence is also necessary to select the most appropriate anti-stigma interventions for South Africa.

Experiences in other settings have consistently shown the positive impact of consumer involvement in increasing awareness ${ }^{39,40}$ and informing policies and research. ${ }^{41} \mathrm{~A}$ literature review examining the active ingredients of an effective anti-stigma intervention for various target groups, for example, showed that the testimonies of consumers was the single ingredient identified by all interventions as having the most significant and lasting impact in reducing stigma. ${ }^{42}$ Furthermore, examination by Reinke and colleagues ${ }^{43}$ into the forms of contact with consumers showed that both in-person and videotaped contact were effective in changing attitudes. Similar studies evaluating and reporting the impact of existing consumer involvement in South Africa could provide the evidence to increase consumer participation, argue for more support for such activities, and determine how best to support consumer involvement across the country.

There is also ample evidence around the world, particularly for schizophrenia, demonstrating the positive impact of educating the youth to reduce stigma. 4,44-46 The World Psychiatric Association's "Open the Doors" initiative to reduce stigma ${ }^{44}$ was particularly influential in implementing youth programmes and demonstrating their impact in various countries. Some of these involved educational programmes by psychiatrists, psychologists and consumers to high school students while others involved teenagers teaching their peers about mental illnesses. A study in New Jersey also showed that an information session for adolescent, developed and facilitated by mental health care users, had a significant impact on changing attitudes. ${ }^{47}$ Youth programmes are therefore making a difference in other parts of the world and similar documented evidence for South Africa is necessary for policy makers in both the health and education sectors to pool resources to support youth programmes in the country.

There are few studies examining such interventions in the criminal justice system. Pinfold and colleagues ${ }^{48}$ studied the impact of a short educational programme to the police force in the UK and found improvements in the attitudes of police officers and their communication with their subjects. Given the high rates of mental illnesses among those who are in the prisons and the significant shortage of nurses caring for the prisoners in South Africa ${ }^{8}$, it is critical that stigma and discrimination is minimized in correctional facilities to ensure the safety of the individual from both prison staff and prisoners. How best to do this effectively, however, is still not known. Evaluation of the existing programmes and dissemination of the results could have a significant impact on planning of services in the correctional system.

With regards to the media, although there is evidence showing the negative impact of media on people's attitudes towards individuals with mental illnesses, there is less evidence demonstrating how media can be used to educate communities and reduce stigma. It is difficult to accurately measure the impact of messages in the media on people's attitudes. Nonetheless, national anti-stigma campaigns with high media coverage have been implemented in various parts of the world (Australia, Canada, New Zealand, United Kingdom, etc.) and appear to be showing positive effects. ${ }^{44,49}$ South African government and non-government organizations are also actively using the media to educate communities of various personal and professional background. However, their effectiveness cannot be known without first knowing the current attitudes towards mental illnesses in South Africa. It is also unknown how much of the population the existing information is reaching. With lack of access to mainstream media in many parts of the country, there is still a need to determine how best to get the same messages across

There is international evidence to support the anti-stigma activities that are already being carried out in South Africa, but whether or not they are appropriate in this context and similar in their effectiveness is still unclear. A crucial question is how mental illness is conceptualized in various parts of the country and how the content of the interventions should vary across the various cultural and age groups. What is considered a mental illness and the beliefs regarding their causes can vary significantly. ${ }^{8-10,50-57}$ For example, mental illnesses is often believed to be the result of bewitchment or a failure to appease one's ancestors, having insufficient faith in one's religion, or a defiant attempt to challenge authority and ascribed roles. Substance abuse and committing sins has also been identified as causes of mental illnesses. Some behaviours are not considered part of a mental illness. Disorders such as depression and anxiety disorders are often viewed as social problems rather than medical illnesses ${ }^{51}$, while in some African cultures, a psychotic episode closely resembles the 'calling' to become a traditional healer. ${ }^{58,59}$ What is considered stigmatizing and how a person is stigmatized thus depends on how mental illnesses are conceptualized.

\section{Conclusion}

The success of any anti-stigma intervention relies heavily on the content and mode of the intervention as well as the selection of an appropriate measure and method to evaluate its impact. One cannot assume that increasing awareness about mental illnesses will lead to change in attitudes and behaviour. Educational programmes in other areas have often shown little effect in changing behaviour. For example, programmes to educate adolescents to practice safe sexual practices to prevent HIV/AIDS infection have not significantly changed adolescent risk behaviour. ${ }^{60-63}$ Similarly, anti-tobacco initiatives to educate the youth about the consequences of smoking have also often failed to reduce smoking. ${ }^{64,65}$ Lessons must be learned from such examples to identify strategies that are likely to have the most impact.

In order to properly assess stigma-reduction interventions, a better understanding of the complex manifestation of stigma in the South African context must first be gained. Strategies to optimize the impact of such interventions can then be developed and evaluated. Promotion of such research and 
subsequent dissemination would make a scientific contribution locally and internationally, allow for stronger evidence-based policy, and inform future planning of antistigma campaigns in South Africa and elsewhere.

\section{References}

1. Bradshaw D, Norman R, Schneider M. A clarion call for action based on refined DALY estimates for South Africa. Editorial. South African Medical Journal 2007;97:438-40.

2. Williams DR, Herman A, Stein DJ, Heeringa SG, Jackson PB, Moomal $H$, et al. Prevalence, Service Use and Demographic Correlates of 12-Month Psychiatric Disorders in South Africa: The South African Stress and Health Study. Psychological Medicine 2007; In press.

3. Kleintjes S, Flisher AJ, Fick M, Railoun A, Lund C, Molteno C, et al. The prevalence of mental disorders among children, adolescents and adults in the western Cape, South Africa. South African Psychiatric Review 2006;9:157-60.

4. Thornicroft G. Shunned: discrimination against people with mental illness. Oxford: Oxford University Press Inc.; 2006.

5. Sartorius N. Stigma and mental health. Lancet $2007 \mathrm{Sep}$ 8;370(9590):810-1.

6. Stuart H, Sartorius N. Fighting Stigma and Discrimination Because of Mental Disorders. In: Christodolous GN, editor. Advances in Psychiatry - 2nd volume. World Psychiatric Association; 2005. p. 7986.

7. Wahl OF. Mental health consumers' experience of stigma. Schizophr Bull 1999;25(3):467-78.

8. Lund C, Kleintjes S, Campbell-Hall V, Mjadu S, Petersen I, Bhana A, et al. Mental health policy development and implementation in South Africa: a situation analysis. Phase 1. Country Report. Cape Town, South Africa; 2008.

9. Doku V, Ofori-Atta A, Akpalu B, Osei A, Ae-Ngibise K, Read U, et al. Country Report of Mental Health Policy Development and Implementation in Ghana. Ghana; 2008.

10. Kigozi F, Ssebunnya J, Kizza D, Green A, Omar M, Bird P, et al. Phase 1 Country Report: A situation analyseis of the menal health system in Uganda. Kampala, Uganda; 2008.

11. Angermeyer MC. Schizophrenia and violence. Acta Psychiatr Scand Suppl 2000;407:63-7.

12. Wallace C, Mullen PE, Burgess P. Criminal offending in schizophrenia over a 25-year period marked by deinstitutionalization and increasing prevalence of comorbid substance use disorders. Am J Psychiatry 2004;161 (4):716-27.

13. Brennan PA, Mednick SA, Hodgins S. Major mental disorders and criminal violence in a Danish birth cohort. Arch Gen Psychiatry 2000;57(5):494-500.

14. Schanda H, Knecht G, Schreinzer D, Stompe T, Ortwein-Swoboda G, Waldhoer T. Homocide and major mental disorders: a 25-year study. Acta Psychiatr Scand 2009;1 10(2):98-107.

15. Shaw J, Hunt IM, Flynn S, Meehan J, Robinson J, Bickly H. Rates of mental disorder in people convicted of homocide. National clinical survey. Br J Psychiatry 2006;188:143-7.

16. Hodgins S, Muller-Isberner R. Preventing crime by people with schizophrenic disorders: the role of psychiatric services. BrJ Psychiatry 2004;185:245-50.

17. Scott H, Johnson S, Menezes P, Thornicroft G, Marshall J, Bindman J. Substance misuse and risk of aggression and offending among the severely mentall ill. Br J Psychiatry 1998;1 72:345-50.

18. Swartz MS, Swanson JW, Hiday BA, Borum R, Wagner HR, Burns BJ. Violence and severe mental illness: the effects of substance abuse and nonadherence to medication. Am J Psychiatry 1998;155(2):22631 .

19. Torrey EF. Violent behavior by individuals with serious mental illness. Hosp Community Psychiatry 1994;45(7):653-62.

20. Swanson J, Swartz M, Esteroff S, Borum R, Wagner R, Hiday V. Psychiatric impairment, social contact, and violent behavior: evidence from a study of outpatient-committed persons with severe mental disorder. Soc Psychiatry Psychiatr Epidemiol 1998;33(Supplement 1):S86-S94.

21. Kakuma R, Kleintjes S, Lund C, Flisher AJ, Goering P, the MHaPP Research Programme Consortium. Development and implementation of mental health policy and law in South Africa: What is the impact of stigma? Presented at 15 th Biennial National Congress of the South African Society of Psychiatrists: 10-14 August 2008. George, South Africa. 2008.

22. Hugo CJ, Boshoff DE, Traut A, Zungu-Dirwayi N, Stein DJ. Community attitudes toward and knowledge of mental illness in South Africa. Soc Psychiatry Psychiatr Epidemiol 2003 Dec;38(12):715-9.

23. Botha UA, Koen L, Niehaus DJ. Perceptions of a South African schizophrenia population with regards to community attitudes towards their illness. Soc Psychiatry Psychiatr Epidemiol 2006 Aug; 1 1 (8):619-23.

24. Lupuwana BW, Simbayi LC, Elkonin D. Psychological services in the Black community of Port Elizabeth in South Africa: Assessment of awareness, attitudes, practices and needs. Journal of Psychology in Africa 1999;25-57.

25. Mavundla TR, Uys LR. The attitudes of nurses towards mentally ill people in a general hospital setting in Durban. Curationis 1997 Jul;20(2):3-7.

26. Mavundla TR. Professional nurses' perception of nursing mentally ill people in a general hospital setting. J Adv Nurs 2000 Dec;32(6):1569-78.

27. Lethoba KG, Netswera FG, Rankhumise E. How professional nurses in a general hospital setting perceive mentally ill patients. Curationis 2006 Nov;29(4):4-11.

28. Pincus FL. Discrimination comes in many forms: Individual, Institutional, and Structural. American Behavioral Scientist 1996;40(2):186-94

29. Corrigan PW, Markowitz FE, Watson AC. Structural levels of mental illness stigma and discrimination. Schizophr Bull 2004;30(3):481-91.

30. Corrigan PW, Watson AC, Heyrman ML, Warpinski A, Gracia G, Slopen N, et al. Structural stigma in state legislation. Psychiatr Serv 2005 May;56(5):557-63.

31. Corrigan PW, Kleinlein P. The Impact of Mental Illness Stigma. In: Corrigan PW, editor. On the Stigma of Mental Illness: Practical Strategies for Research and Social Change. Washington,DC: American Psychological Association; 2005. p. 11-44.

32. Hemmens C, Miller M, Burton VS, Jr., Milner S. The consequences of official labels: an examination of the rights lost by the mentally ill and mentally incompetent ten years later. Community Ment Health J 2002 Apr;38(2):129-40.

33. Burton VS, Jr. The consequences of official labels: a research note on rights lost by the mentally ill, mentally incompetent, and convicted felons. Community Ment Health J 1990 Jun;26(3):267-76.

34. Flisher AJ, Lund C, Funk M, Banda M, Bhana A, Doku V, et al. Mental health policy development and implementation in four African countries. Journal of Health Psychology 2007; 12:505-16.

35. WHO. WHO Assessment Instrument for Mental Health Systems (AIMS) Version 2.1. Geneva: WHO; 2005.

36. WHO. World Health Report 2001, Mental Health: new 
understanding, new hope. Geneva: WHO; 2001.

37. South African Federation for Mental Health. http://www safmh org zal 2008Available from: URL: http://www.safmh.org.zal

38. Ritchie J, Spencer L. Qualitative data analysis for applied policy research. In: Bryman A, Burgess RG, editors. Analysing qualitative data.London: Routledge; 1994. p. 173-94.

39. Corrigan P, Gelb B. Three programs that use mass approaches to challenge the stigma of mental illness. Psychiatr Serv 2006 Mar;57(3):393-8.

40. Corrigan PW, River LP, Lundin RK, Penn DL, Uphoff-Wasowski K, Campion J, et al. Three strategies for changing attributions about severe mental illness. Schizophr Bull 2001;27(2):187-95.

41. Boote J, Telford R, Cooper C. Consumer involvement in health research: a review and research agenda. Health Policy 2002 Aug;61 (2):213-36.

42. Pinfold $V$, Thornicroft G, Huxley P, Farmer P. Active ingredients in anti-stigma programmes in mental health. Int Rev Psychiatry 2005 Apr;17(2):123-31.

43. Reinke RR, Corrigan PW, Leonhard C, Lundin RK, Kubiak MA. Examining two aspects of contact on the stigma of mental illness. Journal of Social and Clinical Psychology 2004;23(3):377-89.

44. Sartorius N, Schulze H. Reducing the stigma of mental illness: a report from a Global Programme of the World Psychiatric Association. Cambridge: University Press; 2005.

45. Watson AC, Otey E, Westbrook AL, Gardner AL, Lamb TA, Corrigan PW, et al. Changing middle schoolers' attitudes about mental illness through education. Schizophr Bull 2004;30(3):563-72.

46. Pinfold V, Toulmin H, Thornicroft G, Huxley P, Farmer P, Graham T. Reducing psychiatric stigma and discrimination: evaluation of educational interventions in UK secondary schools. Br J Psychiatry 2003 Apr;182:342-6.

47. Spagnolo AB, Murphy AA, Librera LA. Reducing stigma by meeting and learning from people with mental illness. Psychiatr Rehabil J 2008;31 (3):186-93.

48. Pinfold V, Huxley P, Thornicroft G, Farmer P, Toulmin H, Graham T. Reducing psychiatric stigma and discrimination--evaluating an educational intervention with the police force in England. Soc Psychiatry Psychiatr Epidemiol 2003 Jun;38(6):337-44.

49. Rosen A, Walter G, Casey D, Hocking B. Combating psychiatric stigma: An overview of contemporary initiatives. Australasian Psychiatry 2000;8(1):19-26.

50. Mwanza J, Sikwese A, ayeya J, Lund C, Bird P, Drew N, et al. Phase I Country Report: Mental health policy development and implementation in Zambia: a situation analysis. Lusaka, Zambia; 2008.

51. Patel V, Musara T, Butau T, Maramba P, Fuyane S. Concepts of mental illness and medical pluralism in Harare. Psychol Med 1995 May;25(3):485-93.

52. Bhana K, Bhana A. Conceptualizations of mental illness by South African Indian adolescents and their mothers.J Soc Psychol 1985 Jun;125(3):313-9.

53. Karasz A. Cultural differences in conceptual models of depression. Soc Sci Med 2005 Apr;60(7):1625-35.

54. Njenga F. The concept of mental disorder: an African perspective. World Psychiatry 2007 Oct;6(3):166-7.

55. Cheetham WS, Cheetham RJ. Concepts of mental illness amongst the rural Xhosa people in South Africa. Aust N Z J Psychiatry 1976 Mar; 10(1):39-45.

56. Patel V. Explanatory models of mental illness in sub-Saharan Africa. Soc Sci Med 1995 May;40(9):1291-8.

57. Lund C, Swartz L. Xhosa-speaking schizophrenic patients' experience of their condition: psychosis and amafufunyana. S Afr J Psychol 1998;28(2):62-70.

58. Buhrmann MV. Thwasa and bewitchment. S Afr Med J 1982 Jun 5;61 (23):877-9

59. Buhrmann M. Xhosa diviners as psychotherapists. Psychotherapie 1977;3(4):17-20.

60. Kirby D, Obasi A, Laris BA. The effectiveness of sex education and HIV education interventions in schools in developing countries. World Health Organ Tech Rep Ser 2006;938:103-50.

61. Paul-Ebhohimhen VA, Poobalan A, van Teijlingen ER. A systematic review of school-based sexual health interventions to prevent STI/HIV in sub-Saharan Africa. BMC Public Health 2008;8:4

62. Yankah E, Aggleton P. Effects and effectiveness of life skills education for HIV prevention in young people. AIDS Educ Prev 2008 Dec;20(6):465-85.

63. Magnussen L, Ehiri JE, Ejere HO, Jolly PE. Interventions to prevent HIVIAIDS among adolescents in less developed countries: are they effective? Int J Adolesc Med Health 2004 Oct; 16(4):303-23.

64. Resnicow K, Reddy SP, James S, Gabebodeen OR, Kambaran NS, Langner HG, et al. Comparison of two school-based smoking prevention programs among South African high school students: results of a randomized trial. Ann Behav Med 2008 Dec;36(3):23143.

65. Thomas R, Perera R. School-based programmes for preventing smoking. Cochrane Database Syst Rev 2006;3:CD001293. 